ISSN electrónico: 2172-9077

DOI: https://doi.org/10.14201/fjc202123312

INTERACCIONES ENTRE LAS PRÁCTICAS AUDIOVISUALES DEL ARTE Y LA CIENCIA

\title{
Interactions between Art and Science Audiovisual Practices
}

Dr. José GÓMEZ-ISLA

Profesor Titular de la Universidad Complutense de Madrid

E-mail: jgomez20@ucm.es

(iD https://orcid.org/0000-0003-1915-933X

Dra. Carmen GONZÁLEZ GARCÍA

Profesora Contratada Doctora de la Universidad de Salamanca

E-mail: cmngonzalez@usal.es

(iD https://orcid.org/0000-0002-9851-3044

Fecha de recepción del artículo: 13/10/2021

Fecha de aceptación definitiva: 13/10/2021

\section{Presentación}

Nuestra mirada de sapiens se ha visto profundamente afectada en cada periodo histórico por los discursos culturales e ideológicos que nos han ido atravesando en tanto que seres sociales. La pertenencia a un momento concreto de la Historia o a una determinada cultura o grupo social, ha determinado en buena medida la manera en que percibimos la realidad que nos rodea.

En consecuencia, nuestra forma de mirar el entorno ha ido variando con el curso de los acontecimientos y las épocas en función de factores muy diversos. Por enumerar solo algunos, capaces de modificar el modo de ver y pensar la realidad, podemos nombrar, entre otros: nuestros propios intereses -ya sean personales o colectivos-, las creencias más arraigadas, pero también los prejuicios, las ideologías dominantes en un determinado contexto histórico, político o cultural, los avances tecnológicos y los descubrimientos científicos, capaces de transformar y redefinir cada época y, no menos importante, nuestro sentido identitario, un insoslayable sentimiento de pertenencia a un determinado colectivo, ya sea familiar, social, cultural o profesional.

De igual modo, a la par que nuestra mirada, también ha ido variando el modo en que representamos lo percibido, ya sea para comprenderlo, dominarlo o incluso transformarlo. La búsqueda de respuestas acerca de los enigmas de la vida, tanto de fenómenos naturales como sociales, arroja algo más de luz cuando intentamos representarlos y comprenderlos con imágenes esclarecedoras. 
Dos de las formas culturales que más nos han ayudado a entender el funcionamiento del mundo (y quien dice "mundo" dice "universo"), reformulando paulatinamente nuestro pensamiento sobre el mismo, han sido, sin ningún género de dudas, el arte y la ciencia. Estas dos miradas, que atienden a intereses aparentemente dispares, son proyectadas sobre una realidad, siempre poliédrica -visible e invisible a la vez-, analizándola e interpretándola para desentrañar su complejidad, y alejarnos así de prejuicios, supersticiones y falsas creencias.

Desde el Renacimiento, y durante más de tres siglos, arte y ciencia han transitado armoniosamente por caminos paralelos, divergentes en ocasiones, pero siempre complementarios, propiciando extraordinarios avances cuando la curiosidad de artistas y científicos confluye y estimula el conocimiento. La historiadora Laura J. Snyder (2017) narra magistralmente en el libro El ojo del observador uno de esos momentos, trazando los recorridos paralelos en las vidas del pintor Johannes Vermeer y el científico Antoni van Leeuwenhoek en la ciudad de Delft en el siglo XVII. Snyder nos sumerge en la cotidianeidad de una sociedad impregnada por la curiosidad científica y la capacidad de inventar artilugios ópticos que pudieran alimentar aún más esa curiosidad. Este contexto haría avanzar en paralelo las investigaciones del pintor, que utilizó la cámara oscura como herramienta auxiliar de su pintura, y las del científico, que observó por primera vez un microorganismo en un microscopio fabricado por él mismo, logrando ampliar, en ambos casos, nuestro conocimiento del mundo con nuevos modos de ver y comprender.

Sabemos también que estudios anatómicos de grandes artistas del Renacimiento, como Leonardo da Vinci o Miguel Ángel, inspiraron los primeros atlas ilustrados de anatomía, como el de Andrea Vesalio -De Humanis Corporis Fabrica- publicado en 1543.

Otra invención netamente renacentista que transformaría radicalmente el modo en que miramos, tratando de representar el mundo de una forma más realista, o puramente "ocularcentrista", fue la invención de la perspectiva (Pallasmaa, 2014). En tanto que sistema de representación visual hegemónico en Occidente durante más de cuatro siglos, los fundamentos de la perspectiva cónica tratarían de aunar en un mismo régimen escópico ambos saberes: el artístico y el científico (Kemp, 1990). Desde entonces, la figura del ilustrador de ciencia o del dibujante especializado en cualquier rama de la tecnología resultará imprescindible para divulgar los descubrimientos científicos, fuese cual fuese su ámbito de conocimiento.

Sin embargo, a finales del XVIII, con la consolidación y aceptación generalizada del método científico, se produciría una división categórica entre las ciencias y las humanidades, lo que levantaría un muro insalvable entre estos nuevos enfoques a la hora de representar sus respectivos objetos de estudio. Como afirma Stefan Collini, "el surgimiento de la angustia ante la posibilidad de que se produjera una fisura semejante en los [dos] tipos de conocimiento (...) puede fecharse en el período romántico, entre fines del siglo XVIII y principios del siglo XIX» (Collini, 2000, p. 9). La tecnología audiovisual, que se iría incorporando progresivamente a partir de la segunda mitad del XIX, ampliará aún más esa brecha tras la presentación pública de la fotografía en la Academia de Ciencias de Francia (París) en 1839. Desde ese momento, la difusión científica se propagará más rápida y fácilmente a través de los nuevos dispositivos visuales de registro y captura, ensanchando aún más el abismo producido entre "objetividad" científica y la subjetividad y la interpretación "artística» (Daston y Galison, 
2007). La escenificación del divorcio entre ambos saberes se evidenciaría en la conferencia de P.W. Snow titulada "Las dos culturas" (Snow, 1963) donde ambos mundos, el científico y el artístico, se miraban desde orillas opuestas sin llegar a comprenderse mutuamente, cuando no se ignoraban abiertamente, la mayor parte de las veces.

Sin embargo, la separación entre estas dos ramas de conocimiento nunca ha sido tan categórica como a priori podría imaginarse. Por ejemplo, uno de nuestros científicos más ilustres, Santiago Ramón y Cajal, se convertiría en un excepcional ilustrador y divulgador de sus propios descubrimientos sobre el sistema nervioso con bellísimos dibujos de neuronas cuando aún no era posible producir registros fotográficos de las muestras observadas al microscopio (Newman, Araque y Dubinsky, 2017). No en vano, su vocación juvenil fue la de formarse en Bellas Artes, cosa que su padre no le permitió. Además de sus elaborados dibujos, el científico intuiría también la importancia de la tecnología audiovisual en la ciencia, aún en ciernes en su época, convirtiéndose en un apasionado de la fotografía. Es de sobra conocida la faceta de Cajal como innovador de la primitiva fotografía en color (placas autocromas) y de otras técnicas de registro fotográfico que intentó aplicar a sus investigaciones histológicas, como la estereoscopia (que restituye fotográficamente la sensación de tridimensionalidad propia de nuestra visión binocular), todas ellas innovaciones que resultaron revolucionarias a principios del XX. Como demuestran sus múltiples artículos sobre técnica fotográfica, e incluso libros completos centrados en fotografía en color (Ramón y Cajal, 1912), su pasión por este medio le llevaría a indagar en un sinfín de técnicas inéditas para tratar de solventar los problemas de representación microfotográfica que le acuciaba como científico.

Cajal llegaría incluso a inventar un proceso fotográfico propio, denominado «retículo microtómico» o "retículo policromático», que nunca llegaría a patentar. Para ello tintaba bloques de seda de $8 \mathrm{~mm}$ con los tres colores primarios de luz -rojo, verde y azul- loncheados con un micrótomo -un instrumento de corte muy preciso utilizado en histología para producir "rebanadas» de apenas micras de grosor en tejidos celulares- y poder observarlos posteriormente al microscopio extendidos sobre placas de vidrio.

La tendencia dominante en ciencia desde principios del S. XIX privilegiaba la exactitud del instrumento de medida sobre cualquier tipo de percepción humana susceptible de resultar engañosa, una tendencia a la que la fotografía contribuiría enormemente. El nuevo giro positivista llevaría a menospreciar la interpretación, explicativa y didáctica, del ilustrador de la ciencia (precisamente por la supuesta inexactitud en su percepción y su falta de rigor en los detalles), a pesar de que, durante siglos, su papel había resultado crucial para divulgación científica.

Sin embargo, y ya en pleno siglo XX, algunos de los prejuicios que había avivado el positivismo también caerían desde los muros más altos. Podemos encontrar muchas excepciones que abrirían espacio a modelos de visualización alternativos a los oficialmente «objetivos» que promovía el método científico anterior, y no menos válidos que los aportados por los instrumentos ópticos habituales de medición y observación. De hecho, en los albores del S. XX encontramos varios casos paradigmáticos de artistas y científicos que, aunque no fuesen de la mano, propondrán intuiciones equiparables para dar nuevas soluciones visuales y lingüísticas a ciertos problemas de percepción sobre el espacio y el tiempo. Ese es el caso, por ejemplo, de Pablo Picasso y Albert Einstein (Miller, 2007). Poniendo en tela de juicio la geometría euclidiana clásica, 
ambos autores intentaron incorporar en sus propuestas modelos alternativos a la visión imperante sobre la realidad que les imponía su propia época. De esta forma, se llegó a formular un "espacio no euclidiano", donde ambos autores iban a producir su mayor contribución (científica y artística) mediante nuevos modelos que incorporan la cuarta dimensión (el tiempo), una magnitud que hasta entonces apenas había sido considerada en el sistema escópico anterior. De este modo, Picasso con sus Señoritas de Aviñón (1907) y Einstein, con la publicación de su Teoría de la relatividad especial (1905) revolucionaron para siempre la visión que actualmente tenemos sobre el mundo contemporáneo y su forma de representarlo.

"La teoría de la relatividad especial de Albert Einstein y Las señoritas de Aviñón de Pablo Picasso, son obras que introdujeron el arte y la ciencia en el siglo XX. Pero más allá de su momento histórico -las dos responden a la tensión entre el pensamiento clásico y el no clásico- entre ambas obras maestras existe una conexión más profunda. Cuando se produce una creación, las fronteras entre las disciplinas se diluyen. La estética se vuelve primordial.» (Miller, 2007, p. 283)

El paralelismo evidente entre estos dos autores y sus obras, no se produce solamente porque sus revolucionarias formulaciones (tanto para la ciencia como para el arte) se fraguasen prácticamente durante los mismos años. Su afán por construir un "relato inédito» de la realidad obedecía también al espíritu de cambio y renovación que en aquella época estaba invadiendo toda Europa. Además, ambos autores bebieron de fuentes de inspiración similares (como los escritos sobre geometría de Poincaré) y se dejaron impregnar por los mismos descubrimientos técnicos y visuales de su época, como la invención del cine o el descubrimiento de los rayos X, lo que, a su vez, daría paso a la representación inédita del cuerpo invisible (Miller, 2007, p. 19).

Sin haber tenido contacto previo entre sí, Einstein y Picasso llegaron a conclusiones similares que pueden extrapolarse a ambos tipos de pensamiento, el visual/ artístico y el científico. Sus particulares formas de indagar producirían, sin ellos saberlo, muchas conexiones interdisciplinares. Y, aunque este no sea el único caso que confirma la regla, sí que nos permite afirmar que la "creatividad» no es territorio exclusivo del arte, sino que la ciencia también plantea propuestas intuitivas, y no menos creativas que las que propone un artista, aunque sus formalizaciones se correspondan con aquella diferenciación que señalaba John Dewey cuando afirmaba que "La ciencia enuncia significados; el arte los expresa” (Dewey, 2008, p. 95).

Lo que está claro es que, tanto en una como en otra disciplina, Picasso y Einstein eliminarían la condición de existencia de un tiempo y un espacio absolutos en el universo. La coexistencia de varias magnitudes de tiempo en un mismo espacio, o la multiplicidad de puntos de vista de forma simultánea en un mismo arco temporal, es algo que inauguraron tanto el cubismo de Picasso como la teoría de la relatividad de Einstein. Estos modelos han tenido una repercusión sin parangón en la forma en que los medios audiovisuales han construido muchos de sus «nuevos relatos». Películas como Inception (2010) o Interstellar (2014), ambas de Christopher Nolan, son buen ejemplo de ello.

Indudablemente, son mucho más numerosos los casos en los que las formulaciones del arte contemporáneo se han visto influidas de forma determinante por los modos inéditos en que la ciencia y los medios tecnológicos han abordado la realidad de forma visual para transformar paulatinamente nuestra concepción del mundo. Ese 
fue el caso, por ejemplo, de la alteración espacio-temporal favorecida por innovaciones como la instantánea o la cronofotografía (de las que Eadweard Muybridge y Étienne-Jules Marey serían pioneros a finales del S. XIX) o la aparición del montaje cinematográfico a principios del XX.

Todas estas innovaciones audiovisuales trastocaron para siempre el espacio homogéneo y unitario de la representación visual del arte, basaba en el cajón escénico albertiano, un modelo que había permanecido prácticamente inalterado desde que se asumieron los principios geométricos y matemáticos de la perspectiva cónica (Alberti, 1435-1436). Este sistema de representación tan arraigado, asumido desde la pintura renacentista hasta el impresionismo de mediados del S. XIX (Kemp, 1990), empezaba a resultar excesivamente "retiniano" para artistas contemporáneos como Marcel Duchamp, ya en los albores del S. XX. Muchos de estos nuevos artistas lo desecharon por servir únicamente como "golosina estética" para el espectador, presentando claros síntomas de agotamiento, por su falta de ideas innovadoras para la nueva era. El modelo clásico, basado como decimos en la perspectiva y el realismo visual, ya no resultaría válido en un mundo contemporáneo que, desde la segunda mitad del S. XIX, había sido alterado por un sinfín de convulsiones y desplazamientos espacio-temporales generados en buena medida por las nuevas tecnologías visuales, los medios de comunicación y los nuevos sistemas de transporte que revolucionaron la sociedad de la época.

Los "caminos de ida", por los que la ciencia y el impulso tecnológico han influido decisivamente en el arte contemporáneo, parecen pues incontestables. Pero, lo que no ha quedado del todo claro hasta ahora, o, al menos, no se ha podido demostrar con igual contundencia, es si existen esos otros "caminos de vuelta", por los que ciertas manifestaciones artísticas pueden haber supuesto una influencia determinante para las intuiciones de la ciencia. Los textos que se presentan en este monográfico se hacen eco de algunas de estas influencias mutuas, así como de las fronteras difusas y móviles que comparten el arte y la ciencia desde una interacción cada vez más estrecha en el seno del universo audiovisual.

La aplicación creciente de la tecnología audiovisual a un buen número de manifestaciones artísticas y científicas durante el S. XX y XXI, mediante sus innovadores modos de producción, compartiendo eventualmente procesos de visualización y registro similares, ha servido para transformar la percepción que ambas disciplinas ciencia y arte- tenían de sí mismas y para variar sustancialmente también la forma de construir sus propios relatos. (Gómez-Isla, 2013, p. 109)

Por esa misma razón, la imagen audiovisual ha servido como catalizador para tender nuevos puentes entre artistas y científicos, y para desplazar a menudo sus fronteras disciplinares respectivas, produciendo, en no pocas ocasiones, un trasvase cada vez más enriquecedor de enfoques sobre el mundo que percibimos y la forma en que lo expresamos. La misma tecnología audiovisual que ahora las hace converger, pero que en otro tiempo, con el positivismo y la fotografía, sirvió para aumentar el abismo entre esas dos culturas, ha resultado ser uno de los vectores del nuevo diálogo entre ambas, algo que John Brockman denominaría «la tercera cultura» (Brockman, 1995). Desde los Estudios Visuales (Foster, 1988; Mitchell, 1994; Gil Martín y González García, 2013) se ha perseguido el análisis comparativo de los distintos modelos de producción audiovisual, empleados tanto en ciencia como en arte u otras manifestaciones culturales, lo que permite generar nuevas sinergias entre estos campos específicos 
de conocimiento. Muestra de ello es el número creciente de publicaciones, grupos de investigación y proyectos educativos que en las últimas décadas han incorporado un enfoque interdisciplinar aunando estos dos ámbitos, de los cuales quizás el más conocido es la revista Leonardo: Journal of the International Society for the Arts, Sciences and Technology fundada en 1968 y publicada por el MIT. Otro ejemplo reciente es el trabajo que Gemma Anderson ha realizado en el Museo de Historia Natural de Londres, investigando el dibujo como una herramienta para el análisis morfológico y sensible de las formas vivientes, investigación que ha recopilado en el libro Drawing as a Way of Knowing in Art and Science (2019). Anderson contextualiza sus estudios sobre las formas naturales a través del arte en una tradición que inicia con Goethe y que en el siglo XX enlaza con Paul Klee. En la introducción de su trabajo da cuenta del reciente ascenso de la investigación científica que incluye el arte en su proceso de indagación (Anderson, 2019, p. 4).

\section{Los artículos de este número monográfico}

Los artículos incluidos en este número plantean análisis concretos y certeros sobre diversos modelos de visualización dispares con los que, a través de la tecnología audiovisual, la ciencia y el arte han intentado dar sentido tanto al mundo que habitamos como a nuestro entramado social. Los enfoques y aproximaciones de estos ensayos sobre los procesos productivos de las tecnologías audiovisuales, muchas veces compartidos entre ambas áreas de conocimiento, han servido para desvelar aquellos códigos visuales y lingüísticos con los que han sido generadas tanto las imágenes artísticas como las científicas. Estos códigos entrecruzados han venido transitando entre ambas orillas desde los albores del modelo visual renacentista, pasando por la irrupción de la fotografía y el cine en la escena contemporánea, hasta la llegada de otros nuevos modelos de visualización como la infografía, el tratamiento digital de las imágenes, el modelado y la animación 3D, o la visualización de datos (VD), crucial en los estudios actuales de biología, astronomía o medicina, por ejemplo.

Uno de los artículos invitados, firmado por Laura Bravo y Juan Carlos Jorge (ambos profesores e investigadores en la Universidad de Puerto Rico), se origina desde un cruce de miradas (la Historia del Arte y la Medicina), con perspectivas aparentemente lejanas -aunque familiares- sobre un mismo fenómeno: la representación del ser humano en su más amplia diversidad corporal. Su investigación, titulada "Mirada científica y mirada artística en la representación de rarezas humanas», se centra en personas con distintas enfermedades congénitas y analiza los intereses disciplinares de ambos enfoques a la hora de representar visualmente a estos individuos, comparando las imágenes de los tratados médicos con las de la pintura de esa misma época, en un arco temporal que va desde el siglo XVI al XVIII. Mientras que en las imágenes científicas, la representación humana se tipifica, sin otorgar relevancia al sujeto individual, en la creación pictórica, en cambio, la identidad personal del individuo va a adquirir un mayor protagonismo, expresando la hondura psicológica del retratado en el contexto social y cultural de su época. En su acercamiento metodológico al problema, los autores plantean una mirada interdisciplinar y centran su atención en personas a quienes en su época se tildó de "monstruos» y a los que la medicina del siglo XXI les adscribe diagnósticos de origen genético-cromosómico, como la rareza de la pequeñez, la 
obesidad mórbida en la niñez, la apariencia no-binaria o la ausencia de extremidades. Abriendo este planteamiento al universo audiovisual, ambos autores proponen que el arte cinematográfico es claro heredero de ese particular acercamiento emocional de la pintura a la representación de la individualidad de personas con enfermedades congénitas. En su caso, el medio audiovisual seguirá caracterizando psicológicamente a esos protagonistas, dotándolos generalmente de una profunda sensibilidad y humanismo.

Nuestra segunda firma invitada es la del catedrático Roberto Therón, especializado en ingeniería informática y visualización de datos (VD). En su ensayo titulado "Visualización de datos: caminos de ida y vuelta entre arte y ciencia en la producción y consumo de imágenes», realiza un lúcido análisis sobre cómo esta práctica ha venido siendo utilizada de manera exponencial, desde finales del S. XX, y, con mucho más ímpetu, a partir de la segunda década del XXI. Aplicada a distintos campos de conocimiento tanto en ciencia (astronomía, medicina, biología) como en artes visuales, la VD cada vez cobra mayor relevancia en otros ámbitos como el periodismo de datos y, por supuesto, la comunicación audiovisual. El ensayo analiza distintos ejemplos en varios periodos históricos donde la visualización de datos estadísticos, aun sin el apoyo de la ingeniería informática, inspirará nuevos mapas conceptuales y "figurativos» tanto en geografía y astronomía como en el ámbito de la estrategia militar, por ejemplo. En todo caso, el autor nos propone, a través de distintos ejemplos, esos "caminos de ida y vuelta» en los que la ciencia ha inspirado modelos visuales para el arte. Pero, en igual medida, da cuenta de otras tantas propuestas artísticas que han servido como fuentes de influencia determinantes para los avances en modelos «figurativos» $\mathrm{y}$ "Conceptuales» en los que se ha apoyado la ciencia. Como conclusión, el ensayo propone la visualización de datos como una oportunidad única para establecer una mayor colaboración futura -a tres bandas- entre las artes visuales, la ciencia y la ingeniería, y conseguir estrechar cada vez más los lazos de entendimiento y comprensión del mundo a través de la imagen.

Por su parte, el artículo firmado por Jaime López-Díez, Gema Bonales Daimiel, Isidro Jiménez Gómez y Francisco José García-Ramos, analiza un tema tan actual como la evolución de la imagen del coronavirus (Covid-19) en el medio televisivo y su comparación con otras imágenes generadas desde la ciencia. Su investigación analiza las estrategias llevadas a cabo por los informativos españoles en períodos sucesivos de la pandemia a la hora de diseñar esas imágenes del virus. Las distintas versiones producidas por creadores infográficos y modeladores 3D para la televisión se inspira de forma generalizada en los hallazgos de la ciencia para, eso sí, dar su propia «versión interpretativa" en las noticias que se han venido produciendo sobre el virus entre 2020 y 2021. Las imágenes de otras epidemias sufridas a lo largo del S. XIX y principios del XX resultaban más inocentes, más simbólicas y menos informadas, ya que los microorganismos (invisibles entonces para la ciencia) se representaban como monstruos siniestros, o colosales esqueletos apocalípticos, que amenazaban a un conjunto de ciudadanos diminutos e indefensos. Ahora, en cambio, las imágenes del Covid-19 que nos llegan a través de los medios de comunicación poseen una innegable influencia de la información científica a través de potentes aparatos de observación y registro, como los microscopios electrónicos, por ejemplo. Pero, a diferencia de las imágenes científicas, ya sean fotografías al microscopio o modelizaciones 3D, defendidas como "objetivas", las imágenes transmitidas por los medios de comunicación van a variar significativamente en función de intereses ideológicos o emocionales que, según el 
caso, estos medios han querido transmitir al conjunto de la ciudadanía. Las conclusiones de los autores del ensayo plantean que las imágenes del virus aparecidas en los informativos televisados exageraron o aminoraron determinadas características (como el color, la apariencia o el tamaño de las espículas del virus) para presentarlo de forma más agresiva y peligrosa en unos casos, o más amable y de menor riesgo, a medida que la pandemia fue remitiendo.

Otros trabajos, por su parte, dan buena cuenta de la «nueva visión» que la ciencia y el arte contemporáneo han incorporado a nuestra sociedad actual mediante la ruptura del espacio unitario y homogéneo del Renacimiento. Esta ruptura, concebida -como ya hemos apuntado- durante la primera década del S. XX, se materializaba con la irrupción del cubismo de Picasso y Braque en el arte o la teoría de la relatividad de Einstein en la ciencia. Así, por ejemplo, el artículo que lleva por título «La puerta videoescénica", firmado por Gustavo Montes, aborda esta nueva concepción narrativa a través de la fragmentación espacio temporal en el ámbito la representación teatral, sobre todo cuando el medio audiovisual se incrusta en el montaje escénico. El ensayo indaga en conceptos como la simultaneidad o la sucesividad -ya sea temporal o espacial-, un hecho que se explora en diversos montajes teatrales donde las pantallas de vídeo se incorporan a la propia narrativa dramática. Como bien apunta el autor de esta investigación, la incorporación del audiovisual a la escena teatral suele introducirse generalmente como algo más que un mero elemento escenográfico. En las tres obras teatrales analizadas, el medio audiovisual pasa a formar parte activa en la construcción del relato, en una inédita dislocación espacio temporal frente a los recursos narrativos propios de los montajes escénicos tradicionales.

El ensayo titulado "El cine 'CliFi' y la rentabilidad de salvar el planeta», firmado por David Vicente Torrico, plantea un análisis de las producciones cinematográficas exhibidas en los últimos 20 años en las carteleras españolas y que tienen como principal temática la emergencia climática. Ante la alerta de la que nos viene avisando la ciencia desde hace décadas sobre los efectos devastadores del cambio climático, el autor se centra en cómo el cine 'CliFi' o "ficción climática» se ha hecho eco de un posible desastre ecológico inminente. El afán de determinadas producciones cinematográficas -documentales y de ficción- por concienciar a los espectadores e introducir este tema en la agenda del debate social se analiza según determinados parámetros (económicos, de género o por su repercusión mediática) para tomar el pulso a la "salud» y la presencia de las que gozan este tipo de temáticas en la gran pantalla.

Por otro lado, la investigación titulada «Comunicación en museos a través de redes sociales durante la pandemia», firmada por Victoria Fernández Fernández, Miguel Ángel Suárez Suárez y Roser Calaf Masachs, plantea un estudio de las estrategias comunicativas seguidas por algunos museos del norte de España (Asturias, Galicia y Cantabria), antes, durante y después del confinamiento domiciliario generado por la pandemia del Covid-19, momento crucial en el que, durante casi tres meses, no pudieron visitarse ni sus salas -con sus fondos patrimoniales y artísticos-, ni disfrutar de sus eventos y actividades de forma presencial. El artículo se centra, sobre todo, en los cambios operados por estas instituciones en su comunicación en redes sociales para acercar virtualmente sus contenidos al conjunto de la ciudadanía. El análisis arroja datos significativos sobre las fluctuaciones de este tipo de comunicación en distintos periodos de pre y pos-confinamiento durante la pandemia. Estos datos explican cómo los museos se vieron obligados a adaptarse a los nuevos modelos de comunicación a 
través de las redes sociales (Facebook, Twitter e Instagram), como consecuencia inevitable de la crisis sanitaria. La investigación, de carácter cuantitativo (con estadísticas segmentadas por tipología de contenidos y volumen de tráfico en redes) y también cualitativo (mediante entrevistas a responsables de los museos), plantea en sus conclusiones cómo una crisis sanitaria como la sufrida a causa del Covid-19 ha obligado a variar significativamente los hábitos de comunicación de las instituciones museísticas, generando nuevos modelos de interacción con su público mediante estrategias inéditas y creativas en el entorno virtual de las redes sociales.

En el ensayo titulado «Quién limpia los pájaros después?», su autora, Elisa Tavares, nos introduce en el singular imaginario plástico del fotógrafo brasileño Tony Genérico. A través de una entrevista semiestructurada con el propio fotógrafo, y del análisis comparativo de su obra -a nivel técnico y conceptual- con la de otros creadores, pioneros de la fotografía ultrarrápida, se inferirán nuevas conclusiones sobre la movilidad de los límites entre arte y ciencia. El análisis técnico y estético de estas obras fotográficas merodea en torno a la importancia de la innovación tecnológica a la hora de descubrirnos fenómenos inéditos para el ojo humano, como el vuelo de los pájaros "en parada" o el aspecto de la salpicadura "congelada" de un fluido, detenida, en este caso, por un flash electrónico de alta velocidad. Precisamente será la mediación fotográfica, al representar de forma inédita esos fenómenos de la naturaleza en movimiento, con afán de esclarecer sus misterios, la que sitúe las producciones visuales de este fotógrafo en un territorio intermedio y difuso entre el arte y la ciencia.

Por último, el artículo que lleva por título «Videojuegos y cambio climático», firmado por María Josep Picó, Esteban Galán-Cubillo y Emilio Sáez Soro, analiza un caso particular de cocreación, a caballo entre el arte y la ciencia, a partir de la creación de videojuegos en el contexto concreto de un living lab universitario. En este ensayo se defiende la producción de videojuegos como el espacio donde se aglutinan e imbrican buena parte de las artes visuales y las disciplinas artísticas tradicionales. En el caso concreto de esta experiencia de cocreación, se ha incorporado además un valor añadido, puesto que los videojuegos creados por distintos grupos de universitarios tenían como temática común la concienciación positiva sobre el cambio climático, proporcionando al posible usuario herramientas de empoderamiento a través del juego que le permitieran abordar modelos de participación ante la emergencia climática y el calentamiento global. Al mismo tiempo, otro de los objetivos de esta experiencia consistió en descubrir hasta qué punto la creación artística, a través de la producción de videojuegos, podría convertirse en vector eficaz e innovador para la divulgación y la comunicación de la ciencia y, a su vez, en elemento clave para la concienciación ciudadana y el cambio social. Fruto de esta experiencia, una de las principales conclusiones de la investigación ha revelado que los propios participantes en este proyecto de creación de videojuegos consideraron el living lab como una fórmula eficaz y enriquecedora a la hora de facilitar el encuentro entre arte, ciencia y sociedad.

\section{Bibliografía}

Alberti, L. B. (1435-1436). De pictura, Libros I, II y III. Edición castellana: De la pintura y otros escritos sobre arte, Madrid, España: Tecnos, 1999.

Anderson, G. (2019). Drawing as a Way of Knowing in Art and Science. Chicago, EE.UU.: Chicago University Press. 
Brockman, J. (1995). The Third Culture: Beyond the Scientific Revolution. New York, EE.UU.: Touchstone.

Brysson, N. (1988). The Gaze in the Expanded Field. En H. Foster (Ed.), Vision and Visuality. Dia Art Foundation Discussions in Contemporary Culture (2) (pp. 87-108). Seattle, EE.UU.: Bay Press.

Collini, S. (2000) Artículo introductorio. En C. P. Snow, Las dos culturas (pp. 5-70). Buenos Aires, Argentina: Nueva Visión SAIC.

Daston, L. y Galison, P. (2007) Objectivity. Cambridge, Massachussetts, EE. UU.: Zone Books, MIT Press.

Dewey, J. (2008). El arte como experiencia. Barcelona, España: Paidós.

Foster, H. (Ed.). (1988). Vision and Visuality. Dia Art Foundation Discussions in Contemporary Culture (2). Seattle, EE. UU.: Bay Press.

Gil Martín, F. J. y González García, C. (2013). Imágenes envenenadas. Consideraciones pragmáticas sobre la impureza visual en las prácticas artísticas. En J. Gómez-Isla (Ed.), Cuestión de imagen. Aproximaciones al universo audiovisual desde la comunicación, el arte y la ciencia (pp. 179-192). Salamanca, España: Ediciones Universidad de Salamanca.

Gómez-Isla, J. (2013). Arte, documento y discurso audiovisual: entre la imagen de la ciencia y la ciencia de la imagen. En J. Gómez-Isla (Ed.), Cuestión de imagen. Aproximaciones al universo audiovisual desde la comunicación, el arte y la ciencia (pp. 79-110). Salamanca, España: Ediciones Universidad de Salamanca.

Jay, M. (1988). Scopic Regimes of Modernity. En H. Foster (Ed.), Vision and Visuality. Dia Art Foundation Discussions in Contemporary Culture (2) (pp. 3-23). Seattle, EE.UU.: Bay Press.

Kemp, M. (1990). The Science of Art. New Haven, EE.UU.: Yale University Press.

Miller, A. I. (2001). Einstein, Picasso: Space, Time and the Beauty That Causes Havoc. New York, EE. UU.: Basic Books.

Mitchell, W. J. T. (1994). Picture Theory. Essays on Verbal and Visual Representation. Chicago, EE.UU.: Chicago University Pres.

Newman, E. A., Araque, A. y Dubinsky, J. M. (Eds.). (2017). The Beautiful Brain. The Drawings of Santiago Ramón y Cajal, New York, EE. UU: Abrams.

Pallasmaa, J. (2014). Los ojos de la piel. La arquitectura y los sentidos. Barcelona, España: Gustavo Gili.

Ramón y Cajal, S. (1912). La fotografía de los colores. Bases científicas y reglas prácticas. (Reimpreso en Madrid, España: Libros Clan A. Gráficas, S.L., 1994)

Snow, C. P. (1963) The two cultures. Cambridge, EE. UU.: Cambridge University Press, 1988.

Snyder, Laura J. (2017). El ojo del observador. Barcelona, España: Acantilado. 